antibiotics. ${ }^{3}$ For those whose sepsis fails to respond to antibiotics incision and drainage is recommended..$^{12}$ The theoretical advantages of this approach are that it allows the loculi within the cavity of the abscess to be broken down and that it allows dependent drainage, usually with a corrugated drain, to be established.' This treatment causes problems for some families because it results in the absence of the mother from home, sometimes for two or three days. Even if primary closure of the abscess is performed this still requires a general anaesthetic and an overnight stay in hospital.

Treating breast abscesses in lactating women by aspiration is not new. Florey et al successfully treated 10 small abscesses ( $<10 \mathrm{ml}$ of pus) by daily aspiration and administration of large doses of penicillin into the cavity of the abscess. ${ }^{+}$Large abscesses (which would have included all those treated in this study) were, however, treated by surgical drainage.

This study has shown that even large breast abscesses can be effectively treated by repeated aspiration and oral antibiotics. This suggests that breaking down loculi and dependent drainage may not be as important as has been suggested, ' and treatment by aspiration may prove more convenient for at least some lactating mothers.

1 Preece PE. The breast. In: Cuschieri A, Giles GR, Moosa AR, eds. Essential surgical practice. Bristol: Wright, 1982:811-31.

2 Scholefield JH, Duncan JL, Rogers K. Review of hospital experience of breast abscesses. Br f Surg 1987;74:469-70.

3 Benson EA. Breast abscesses and breast cysts. Practitioner 1982;226:1397-1401. 4 Florey ME, Macvine JS, Bigby MAM. Treatment of breast abscesses with penicillin. Br Med f 1946;ii:846-8

(Accepted 15 Seplember 1988)

\title{
Sprinting can seriously damage your health
}

\section{P E Stevens, C D Pusey, D J Rainford}

Department of Renal

Medicine, Princess Mary's

RAF Hospital, Aylesbury,

Buckinghamshire

HP22 5PS

P E Stevens, MRCP, senior specialist

D J Rainford, FRCP, consultant

Department of Medicine, Royal Postgraduate

Medical School,

Hammersmith Hospital, London W12 0NN

C D Pusey, MRCP, senior lecturer

Correspondence to: Squadron Leader Stevens
Sustained violent exercise may lead to rhabdomyolysis even in normal muscle cells, usually in the presence of precipitating factors such as fasting, fever, alcohol, or viral infection. ' We describe a fit young man who developed acute renal failure after exertion on two occasions separated by two years.

\section{Case report}

A 23 year old physical training instructor ran two $400 \mathrm{~m}$ sprints on a cool afternoon. Soon afterwards he felt unwell with tenderness in the abdominal muscles, buttocks, and flanks. He passed little urine over the next four days. On admission to hospital six days after the sprints his serum concentration of creatinine was $1160 \mu \mathrm{mol} / \mathrm{l}$, potassium $4.8 \mathrm{mmol} / \mathrm{l}$, creatine kinase $90 \mathrm{IU} / \mathrm{l}$, aspartate transaminase $12 \mathrm{IU} / \mathrm{l}$, urate $0.59 \mathrm{mmol} / 1$, calcium $2.17 \mathrm{mmol} / 1$, and phosphate $2.0 \mathrm{mmol} / \mathrm{l}$. He made a spontaneous recovery from acute renal failure and 14 days later the results of a renal biopsy were consistent with acute tubular necrosis secondary to rhabdomyolysis. His renal function returned to normal, and he resumed a full sporting programme. There was no relevant drug, personal, or family medical history, and he had previously undergone two general anaesthetics without event. He had been a schoolboy football international and started competitive athletics at the age of $20 \mathrm{He}$ regularly noticed pain and tenderness in the buttocks after $400 \mathrm{~m}$ and $800 \mathrm{~m}$ races but never after longer or shorter distances.

Two years later he again ran two $400 \mathrm{~m}$ sprints on a cool afternoon. He had avoided alcohol for several days and ensured adequate hydration and nutrition. Again he developed pain and tenderness in the buttocks and flanks and was admitted to hospital 24 hours later. Urine dipstick testing showed protein $(4+)$ and blood $(3+)$; myoglobin was not looked for at that stage. Investigations on admission showed a serum concentration of creatinine of $380 \mu \mathrm{mol} / \mathrm{l}$, potassium $4.4 \mathrm{mmol} / \mathrm{l}$, and creatine kinase $107 \mu \mathrm{mol} / \mathrm{l}$. His renal function deteriorated, and he was referred to the renal unit, where he required haemodialysis for one week before recovering function. Results of subsequent investigations were all normal and included measurements of calcium, phosphate, and urate concentration, thyroid function, and activity of muscle enzymes including debrancher enzymes and carnitine palmityl transferase; ischaemic lactate tests; electromyography and nerve conduction studies; and a phosphate nuclear magnetic resonance scan. The results of muscle biopsy were compatible with rhabdomyolysis; phosphorylase was present in normal amounts, there was no excess of glycogen, and his mitochondria seemed normal. Two months after recovery creatine kinase activities before and after a $2.4 \mathrm{~km}$ jog were $97 \mathrm{IU} / 1$ and $115 \mathrm{IU} / 1$ respectively and rose to $183 \mathrm{IU} / 1$ after 24 hours. No myoglobinuria was detected after exercise, though he was tender over the erector spinae and hamstring muscles and feverish $\left(38 \cdot 7^{\circ} \mathrm{C}\right) 16$ hours after exercise.

\section{Comment}

The unusual feature of this case was the development of acute renal failure on two separate occasions after two $400 \mathrm{~m}$ sprints. The presumed cause on each occasion was rhabdomyolysis, as suggested histologically by renal and muscle biopsies. The creatine kinase activity was, however, normal six days later on the first occasion and only one day after exertion on the second. $\mathrm{He}$ developed a small but definite rise in creatine kinase activity after exercise, but this is well described in normal individuals. We could not find any of the known causes of rhabdomyolysis, neither could we show any abnormality of muscle function despite extensive investigation, including enzyme assays, biopsies, and phosphate nuclear magnetic resonance scanning. No precipitating factors such as fasting, fever, alcohol, or viral infection were present on either occasion. The precise cause of his acute renal failure remains unknown; he might have an unrecognised metabolic defect or may be capable of exerting himself beyond normal limits.

We thank the director general of medical services (RAF) for permission to publish and Dr Anita Harding for performing the muscle investigations. C D Pusey is a Wellcome senior research fellow in clinical science.

1 Knochel JP. Rhabdomyolysis and myoglobinuria. Semin Nephrol 1981;1:75-86.

(Accepted 19 September 1988) 